changing circumstances as those to whom we have entrusted our material interests and, therefore, the full consequences have not yet been seriously felt, chiefly owing to the war-time increase in earnings from $£ 1,734,000,000$ in 1938 to $£ 2,930,000,000$, that is, approximately 70 per cent. The following figures show that the lower income groups have benefited most, and therefore, there is no justification for the doctor-patient-fee relationship to be discarded, at a time when the public has been able to save $£ 9,000,000,000$, of which $£ 3,500,000,000$ were "small savings," in spite of more being spent on beer, tobacco, clothing and entertainment.

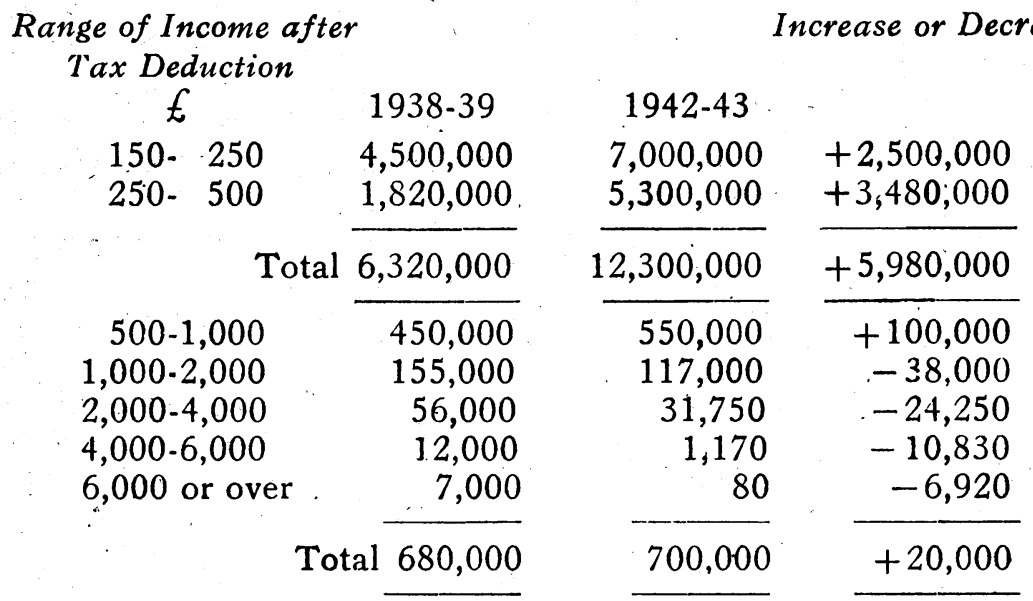

In view of these facts, one is left wondering what is the real aim of those who seem intent on undermining the spirit of independence which was such an estimable characteristic of the British people until a multiplicity of grandiose schemes were announced as being "free for all.".

Yours faithfully,

H. RICHARD BICKERTON.

LIVERPOOL,

July 20, 1945.

\title{
HETEROPHHORIA AND NEUROSIS IN FLYING PERSONNEL
}

To the Editors of The BRITISH Journal of Ophthalmology.

DEAR SIRS, - We have read with interest the above article which appeared in the Brit. Jl. Ophthal. of March, 1945, but feel that the 
conclusions at which the authors arrive should not be allowed to pass without comment.

The article states that of 5.7 cases of aircrew personnel presenting themselves on account of certain ocular symptoms, and in whom some degree of ocular muscle imbalance was demonstrable (by means of the Maddox Rod test), no less than 50 were found as a result of investigation by the usual means of " comprehensive interview and examination" to be suffering from definite well-marked psychological illness.

In these cases, three variable factors are dealt with :-

1. Certain ocular symptoms.

2. Ocular muscle imbalance (heterophoria).

3. The general condition of the patient (with special reference to his psychological state).

We feel that the article does little to clarify the inter-relationship between these factors, particularly as the ophthalmic data supplied are incomplete.

As the authors themselves state:-(1) Small degrees of heterophoria are so common as to be considered almost physiological, and (2) heterophoria may be present without causing any symptoms. One must therefore naturally ask whether in the 57 cases mentioned the ocular symptoms presented were really due to the heterophoria present? None of the presenting symptoms listed in Table 2 of the article, with the probable exception of diplopia, need be due to heterophoria. Moreover, such vague symptoms as " Faulty landing," "Eye strain," "Deteriorating vision," etc., mean nothing unless properly analysed: In fact, most-of the symptoms given might be due to a pure ocular neurosis, or to ordinary fatigue. When such symptoms occur in a patient who is found incidentally to demonstrate a minor or even major degree of heterophoria (as tested by the Maddox Rod) it by no means follows that the heterophoria is responsible for the symptoms. A thorough and comprehensive history and ophthalmic examination are essential before arriving at a satisfactory conclusion.

Of the four illustrative cases described,-case 1, although incomplete, and without information as to the refraction, is, we agree, consistent with the underlying cause of mental fatigue, and is probably a fairly typical case of esophoria due to spasm of convergence. Such a case we would not consider to be in any way suitable for, nor in need of, orthoptic treatment.

The one prism dioptre of hyperphoria present in case 2 cannot, we consider, be regarded as the cause of the symptoms, and such a case is obviously not to be assisted by orthoptic treatment.

The ocular information about case 3 is so inadequate that comment is impossible. Furthermore, in our experience, the job of 
air bombers does not require the possession of a high standard of binocular vision. They are therefore unlikely to experience difficulty in carrying out their duties even if suffering from a symptomproducing heterophoria.

This same remark applies also to case 4. The job of air gunner is primarily a monocular one, in so far as the sighting of his gun is concerned, and therefore the refinements of binocular vision are not of any real importance. Quite apart from this, the history of case 4 points to a diagnosis of mental fatigue, and not an eye condition.

If these cases quoted are a fair representation of the 57 cases dealt with, the conclusions drawn from them cannot be regarded as particularly reliable.

In our experience of heterophoria among flying personnel, we find thát cases fall into two main groups :-

1. Types which can be caused by extra-ocular factors, such as fatigue or worry, often with a well marked neurotic background :-

(a) Convergence insufficiency (especially if associated with esophoria).

(b) Esophoria of the "spasm of convergence" variety.

It should be pointed out that these two varieties of heterophoria show a dynamic factor as opposed to a purely static one. It is usually not difficult in these cases to decide whether the case needs:-

(a) Rest.

(b) Reference to a neuro-psychiatrist for his opinion as to psychiatric treatment, or

(c) Ophthalmic treatment, including orthoptic treatment.

Judgement depends entirely on the past history of the case, the type of symptoms present, and the result of a full ophthalmic examination.

It should be emphasised that it is only in a certain percentage of cases of convergence insufficiency and esophoria that a purely extraocular cause exists.

2. Types which cannot be primarily caused by psychological factors, although the onset of symptoms (due to decompensation) may be determined by unusual emotional stress, fatigue, etc. :-

(a) Periodic Divergent squint.

(b) Periodic Convergent squint.

(c) Hyperphoria.

(d) Most cases of Esophoria and Exophoria.

These cases will respond to proper ophthalmic treatment, and in most cases may be completely cured.

The differential diagnosis of these two classes of heterophoria and the decision as to treatment present no problem if the symptoms, history, and ophthalmic findings are co-related as a whole. The latter should include a study of the state of binocular vision, and 
the degree of "fusional reserve" or "Duction power". and an examination of the stereoscopic vision.

In this respect, we would state that an individual who has a demonstrable heterophoria (as measured by the Maddox Rod test) may be in a state of:-

(a) Full compensation (Symptom-free).

(b) Partial decompensation (Symptom-producing).

By full compensation we mean that the tendency for the visual axes to deviate is kept in check by wholly sub-conscious factors, and in consequence symptoms do not occur. When a case of heterophoria begins to lose its state of full compensation (i.e., when the tendency for the visual axes to deviate can no longer be kept in check by sub-conscious eftort), then the following symptoms may occur as the effort to maintain parallelism of the visual axes becomes conscious :-

(a) Headaches and ocular fatigue, especially referable to the use of the eyes for concentrated work.

(b) blurred vision, usually periodic, which is a forerunner of :-

(c) diplopia, occurring especially when shifting the gaze from a distant to a near object, or vice-versa.

A psychological illness cannot, we consider, produce per se a state of static deviation of the visual axes, although it may be, and often is, one of the factors in producing symptoms of decompensation in a previously well-compensated case.

In cases of demonstable heterophoria, of a greater or less degree which are discovered as a result of a full ophthalmic examination to be well compensated, if ocular symptoms are present they are not normally regarded by us as caused by the heterophoria, unless there is strong confirmatory evidence in the history.

Admittedly it may be difficult in a borderline type of case, e.g., one of slight convergence weakness associated with defective stereopsis, to be absolutely dogmatic as to whether or not the symptoms are due to the heterophoria present. In such cases it is our custom not to give a course of orthoptic treatment unless the result of a psychiatric examination shows the absence of psychological illness. It is only in a small percentage of the cases passing through our hands, however, that this doubt exists.

In conclusion, we agree that the practice of prescribing orthoptic or other ophthalmic treatment for cases of heterophoria indiscriminately, and without reference to the principles we have mentioned, is to be condemned, and is particularly dangerous among flying personnel.

At the same time, the responsibility for decision as to treatment must rest with the Ophthalmologist in the first instance, although as we state above, consultation with a neuro-psychiatrist is indicated in certain classes of case. 
Finally, it is noteworthy that the authors state that in their series only "acquired" cases of heterophoria as opposed to " inherent" cases are considered. It would be interesting to know how they arrive at this distinction.

It would also be of interest to know how the 57 cases were selected.

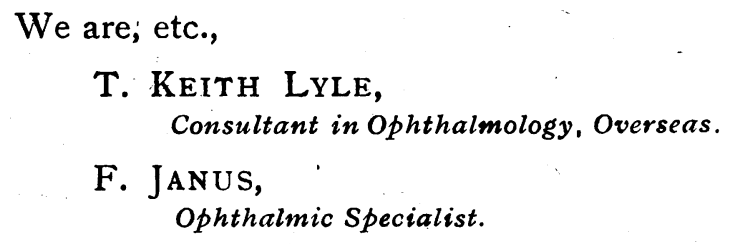

COMMAND MEDICAL BOARD,

' ROYAL AIR FORCE,

MIDDLE EAST FORCES.

\section{NOTES}

Oxford Ophthalmo- Mr. P. G. Doyne has been elected Master of logical Congress the Oxford Ophthalmological Congress for an extra year, and Dr. Bernard Samuels, Deputy Master.

Appointment

Special Notice

Mr. F. J. LAVERY, has been appointed lecturer in ophthalmology at the National University of Ireland.

WE are asked by the Ministry of Information to state that the fact that goods made of raw materials in short supply owing to war conditions are advertised in this journal should not be taken as an indication that they are necessarily available for export. 